\title{
Article \\ Steel Reinforcing Bar and Steel Fibers Content Effect on Tensile and Electrical Behaviors of Strain-Hardening Cement Composite (SHCC) with MWCNTs in Direct Tension
}

\author{
Dong-Hui Kim ${ }^{1}$, Wan-Shin Park ${ }^{2}{ }^{\mathbb{D}}$, Sun-Woo Kim ${ }^{2}{ }^{\mathbb{D}}$, Moon-Sung Lee ${ }^{3} \mathbb{D}$, Soo-Yeon Seo ${ }^{4}(\mathbb{D}$ and \\ Hyun-Do Yun ${ }^{1, *(D)}$ \\ 1 Department of Architectural Engineering, Chungnam National University, Daejeon 34134, Korea; \\ lmamba14@naver.com \\ 2 Department of Construction Engineering Education, Chungnam National University, Daejeon 34134, Korea; \\ salshin@cnu.ac.kr (W.-S.P.); sw.kim@cnu.ac.kr (S.-W.K.) \\ 3 School of Architecture \& Architectural Engineering, Hanyang University Erica, Ansan 15588, Korea; \\ moonlee@hanyang.ac.kr \\ 4 Department of Architectural Engineering, Korea National University of Transportation, \\ Chungju 27469, Korea; syseo@ut.ac.kr \\ * Correspondence: wiseroad@cnu.ac.kr; Tel.: +82-42-821-5622
}

\section{check for} updates

Citation: Kim, D.-H.; Park, W.-S.; Kim, S.-W.; Lee, M.-S.; Seo, S.-Y.; Yun, H.-D. Steel Reinforcing Bar and Steel Fibers Content Effect on Tensile and Electrical Behaviors of StrainHardening Cement Composite (SHCC) with MWCNTs in Direct Tension. Appl. Sci. 2021, 11, 2446. https://doi.org/10.3390/app11052446

Academic Editor:

Togay Ozbakkaloglu

Received: 3 February 2021

Accepted: 5 March 2021

Published: 9 March 2021

Publisher's Note: MDPI stays neutral with regard to jurisdictional claims in published maps and institutional affiliations.

Copyright: (c) 2021 by the authors. Licensee MDPI, Basel, Switzerland. This article is an open access article distributed under the terms and conditions of the Creative Commons Attribution (CC BY) license (https:// creativecommons.org/licenses/by/ $4.0 /)$.
Featured Application: The development of a cement-based strain-detecting sensor and structural health monitoring (SHM) for civil infrastructures using cement-based strain-detecting sensors.

Abstract: This research examines the influence of an embedded steel reinforcing bar and micro steel fibers on the tensile and electrical properties of polyethylene (PE) fibers reinforced cement composite dumbbell-shaped specimens with multi-walled carbon nanotubes (MWCNTs) in direct tension. The cement composites are reinforced with 0.75 vol.\% PE fibers to achieve a strain-hardening performance in direct tension and $1.0 \mathrm{wt} \%$ MWCNTs are incorporated to give the electrical conductivity into the cement composites. To investigate the steel bar and steel fibers effect on the electrical behavior of synthetic PE fiber reinforced strain-hardening cement composites (PE-SHCCs), a round bar with a diameter of 4 or $7 \mathrm{~mm}$ is placed at the center of specimen's cross-section. Additionally, steel fibers' content of $0,0.5$ and 1.0 vol.\% are added into the PE-SHCC mixtures. The test result indicates that the addition of steel fibers improves the tensile strength and electrical behavior of synthetic PE fiber reinforced SHCC. The self-sensing ability of PE-SHCC with $1.0 \%$ steel fibers is improved by the presence of the embedded steel bar before an initial crack while the reinforced PESHCC specimens were less sensitive as the tensile strain increased after the initial crack. The optimal linear regressions between fractional changes in resistivity (FCR) and tensile strain were achieved for PE-SHCC containing $1.0 \%$ steel fibers.

Keywords: strain-hardening cement composite (SHCC); steel bar; electrical behavior; tensile property; multi-walled carbon nanotubes (MWCNTs); steel fibers; self-sensing

\section{Introduction}

In the last few decades, multifunctional cement composites, in particular, self-sensing cement composites have been proposed [1-3]. The smart cement composite can be manufactured by incorporating functional fillers, such as steel fibers [4], nickel [5] and carbon [6], etc., into the cement matrix to endow the conventional cement composite with a conductive performance. In general, it is reported that the carbon conductive fillers have better durability and conductive performance [7].

Since Chen and Chung [8] proposed the self-sensing cement composite made with the adding of carbon fiber, many researchers [9-12] have tried to improve the self-sensing performance of cement composites and have investigated the factors affecting the self-sensing 
properties of cement composites. Yoo et al. [9] investigated the effect of the carbon-based nanomaterial types such as graphite nanofibers, multi-walled carbon nanotubes (MWCNTs) and graphene, on the electrical properties of cement paste with water-to-cementitious material ratio of 0.35 . The test results indicated that the addition of MWCNTs was the most effective to improve the self-sensing capacity of the cement paste. Dong et al. [10] explored the feasibility of using commercial conductive rubber as a conductive filler for self-sensing cement composite with low cost and easy manufacture. It is concluded that the addition of more than $1.28 \%$ conductive rubber fibers into cement matrix could significantly improve electrical conductivity of cement composites. Yin et al. [11] planed and conducted an experimental program to increase self-sensing capacity of carbon nanotube (CNT) cement-based materials by the simultaneous addition of Ni nanofibers with low content. They concluded that the addition of $\mathrm{Ni}$ nanofibers increases the conductivity, sensitivity, linearity and repeatability of cement composite with CNT. Yang et al. [12] examined the feasibility of using waste iron power as conductive filler to produce the self-sensing cement composite in lieu of more expansive fillers such as carbon fibers and CNTs. The experimental studies presented that the gauge factor for the composites increases with increasing iron powder content and were comparable to those of self-sensing cement composites containing a small volume fraction of CNT. Several review papers $[1-3,13,14]$ report that significant factors affecting the self-sensing properties of cement composites are conductive filler type, filler's dispersion, electrode arrangement method, electrical resistivity measurement method, curing age, moisture content, temperature and so on.

Recently, potential application of self-sensing cement composites for structural health monitoring (SHM) has been evaluated [15-20]. Self-sensing cement composite for SHM can be used in bulk form, sensor and coating form.

The application of self-sensing cement composite in bulk form means that the selfsensing cement composite is cast into the whole structure or component. Sarwary et al. [15] tested six large-scale reinforced mortar beams with carbon fibers or MWCNTs to assess the self-sensing capability of reinforced large-scale beam specimens under flexural loading scenario. They suggested that carbon fibers are more effective than MWCNTs as conductive fillers in reinforced self-sensing composite beam due to lower cost, ease mixing and self-sensing property. Howser et al. [16] investigated the self-sensing property of shear-critical column with self-consolidating carbon nanofiber concrete under cyclic loadings. It is reported that in the shear-dominant column cast wholly with carbon nanofiber reinforced concrete, carbon nanofibers restrict the growth of nano-cracks and improve the self-sensing performance.

The self-sensing cement composite can be prefabricated into small-size sensor element and then is embedded into the structure. Roopa et al. [17] developed hybrid nanomaterial cement-based composite sensors and investigated the feasibility of using the sensor for SHM. The nanomaterials used in the study consist of MWCNTs, carbon fibers and Graphene. Dong et al. [18] examined the piezoresistive behaviors of carbon black cement-based sensors embedded in unreinforced small-scale concrete beams under flexural bending load. The test results demonstrated that during the stress monitoring of the concrete beam, the fractional changes in resistivity (FCR) values of sensors in both the flexural compression and tension zones were consistent with the flexural stress changes at acceptable sensitivity and reversibility.

The self-sensing cement composite for existing structure or components can be coated on the surface of a structure or member. The application of self-sensing cement composite as coating form can be found in several studies [19,20]. Wen and Chung [19] used the carbon fiber reinforced cement composite (CFRCC) on the compression side of cement mortar prismatic beam in coating form to monitor the compressive strain of beam specimen under flexure. It is found that the CFRCC coated on a mortar substrate is effective as a strain sensor. Wang et al. [20] proposed a new CFRCC-strengthened reinforced concrete (RC) beam model. CFRCC layer (30, 60 and $90 \mathrm{~mm}$ ) in the tensile side of RC beam was used for strengthening and monitoring the damage of RC beam under monotonic and fatigue 
loadings. They concluded that the damage condition in the CFRCC-strengthened RC beam could be monitored by electrical resistance variation.

As described above, the self-sensing cement composite can be used both as structural material and sensor. A lot of research has concentrated on the self-sensing performance of cement composite used as a sensor under different stress conditions such as compression, tension and flexure. Unfortunately, the study on self-sensing cement composite member used in bulk form has rarely been conducted due to high cost. However, the bulk form possesses simple construction technology, good mechanical property and sensing performance, which has a wide application foreground [14]. When using the self-sensing cement composite as a structural material, i.e., bulk form, the effect of the steel reinforcement in the structural components on the self-sensing property should be evaluated because a structural member is reinforced with longitudinal and transverse steel reinforcement. Wen and Chung [21] reported that the effectiveness for the flexural strain-sensing of carbon fiber reinforced cement prismatic specimens was enhanced by the presence of embedded steel reinforcement on the tensile side. Despite a number of studies conducted on the self-sensing cement composite, little study has been focused on investigating the steel reinforcement effect on the electrical and sensing properties of cement composites.

Strain-hardening cement composite (SHCC) is a novel construction material which is characterized with excellent mechanical performances such as distinctive tensile stressstrain response through strain-hardening behavior, multiple fine cracking behavior and high energy absorption under excessive tension loading conditions [22,23]. Recently, numerous researchers have been interested in the self-sensing properties of SHCCs [24-26]. Compared with the conventional cement composite, SHCC can achieve a higher strain measuring range under various stress scenario such as tension, compression and flexure. The advantage of SHCC is due to the crack damage mitigation property by stress redistribution and crack bridging of reinforcing fibers in the SHCC matrix. Reinforcing fibers in the cement composite are a significant factor to determine the mechanical properties, and in particular, the strain capacity and cracking behavior. It was demonstrated that a hybrid combination of steel and synthetic fibers enhances the resistance to both nucleation and growth of cracks [27].

In this study, the tensile and electrical properties of hybrid steel and polyethylene (PE) fibers reinforced strain-hardening cement composite with $1 \%$ MWCNTs was investigated. This paper is aimed at studying the effect of the influence of steel reinforcing bar and micro steel fibers on the self-sensing ability of PE fibers reinforced strain-hardening cement composite (PE-SHCC).

\section{Materials and Testing Procedure}

\subsection{Materials and Mixture Proportion}

The raw materials used in the production of the SHCC were ordinary Portland cement (Type I) from Hanil Cement Co. Ltd. in South Korea. The micro silica sand with a mean grain size of $120 \mu \mathrm{m}$ was added in the cement matrix at a sand/cement (S/C) ration of 0.4 by mass. Polycarboxylate superplasticizer (SP) was incorporated into cement matrix to achieve an average flow value of about $300 \mathrm{~mm}$ in the fresh cement mortar. Polyethylene (PE) fibers were used at $0.75 \mathrm{vol} \%$ to improve the tensile strength and strain capacity of cement composite. The PE fiber is $15 \mathrm{~mm}$ length and $12 \mu \mathrm{m}$ diameter, and tensile strength of $2.5 \mathrm{GPa}$. Steel fibers were added into PE-SHCC mixtures at both dosages $(0.5 \mathrm{vol} . \%$ or $1.0 \mathrm{vol} . \%$ ) to evaluate the effect of steel fibers on tensile and electrical properties of PESHCC. The steel fiber is $13 \mathrm{~mm}$ length, $200 \mu \mathrm{m}$ diameter and tensile strength of $2.65 \mathrm{GPa}$. A commercially available liquid-type MWCNTs were incorporated as functional fillers to give the conductivity of PE-SHCC and improve the self-sensing capacity. The MWCNTs from Chengdu Organic Chemicals Co. Ltd. in Chengdu, China have inside diameter of $5-15 \mathrm{~nm}$, outside diameters of higher than $50 \mathrm{~nm}$ and lengths of 10-20 $\mu \mathrm{m}$.

The detailed constituents and mass proportions of SHCC mixtures are presented in Table 1. Three mixes were prepared to investigate the steel fiber effect on the tensile and 
electrical properties of PE-SHCCs. Each mix is designated to identify differenced in steel fiber content in the PE-SHCC mixtures. For example, PE-SHCC-SF05 indicates PE-SHCC mixture with a 0.5 vol. $\%$ steel fibers.

Table 1. Mix proportion of polyethylene fiber reinforced strain-hardening cement composites (PE-SHCC).

\begin{tabular}{cccccccc}
\hline Mix Designation & Cement & Water & Silica Sand & SP & PE $^{2}$ & SF $^{2}$ & MWCNT $^{3}$ \\
\hline PE-SHCC-SF00 & 1.0 & 0.3 & 0.4 & 0.02 & 0.75 & 0.0 & 1.0 \\
PE-SHCC-SF05 & 1.0 & 0.3 & 0.4 & 0.02 & 0.75 & 0.5 & 1.0 \\
PE-SHCC-SF10 & 1.0 & 0.3 & 0.4 & 0.02 & 0.75 & 1.0 & 1.0 \\
\hline
\end{tabular}

${ }^{1}$ Total water, the sum of mixing water and additional water from liquid-type multi-walled carbon nanotubes (MWCNTs), ${ }^{2}$ percentage of total mix volume, ${ }^{3}$ percentage of weight of cement.

\subsection{PE-SHCC Mixing and Specimen Preparation}

The cement and micro silica sand were first poured and mixed using a 10-L conventional mortar rotary mixer for $1 \mathrm{~min}$ so that the dry ingredients were well mixed. Water and liquid-type MWCNTs were then added, mixed for $3 \mathrm{~min}$, followed by the SP addition and mixing for $5 \mathrm{~min}$. Finally, reinforcing fibers such as PE and steel fibers were incorporated into fresh mortar and mixed for $3 \mathrm{~min}$. The fresh PE-SHCC mixture were cast into oiled steel molds and vibrated to ensure good compaction. The cast specimens were kept in the molds covered with plastic sheet for $24 \mathrm{~h}$ before they were demolded and then stored in standard curing chamber with $95 \%$ relative humidity and temperature of $20^{\circ} \mathrm{C}$ for 28 days.

The flow table test was performed on fresh PE-SHCC with different contents of steel fibers to evaluate the workability of each mixture using ASTM C230, "Standard Specification for Flow Table for Use in Tests of Hydraulic Cement." Average flow diameter recorded was $165 \mathrm{~mm}, 190 \mathrm{~mm}$ and $215 \mathrm{~mm}$, respectively for PE-SHCC-SF00, PE-SHCCSF05 and PE-SHCC-SF00.

As shown in Figure 1a, nine dumbbell-shaped specimens were prepared for each composition. Among the nine specimens, three specimens were plain PE-SHCC specimens to examine steel fiber effect on tensile and electrical properties. The other ones were used for evaluating the steel reinforcement bar effect on the electrical property. The round steel bar with diameter of 4 or $7 \mathrm{~mm}$ was reinforced at the center of each dumbbell-shaped specimen.

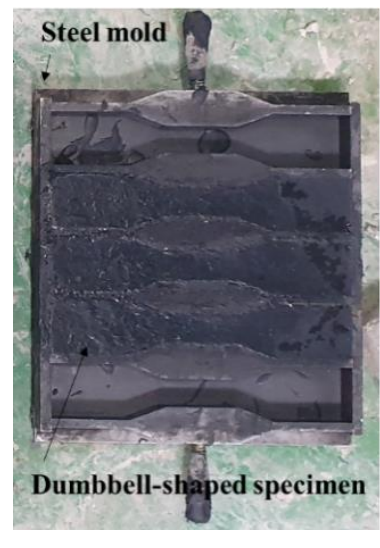

(a)
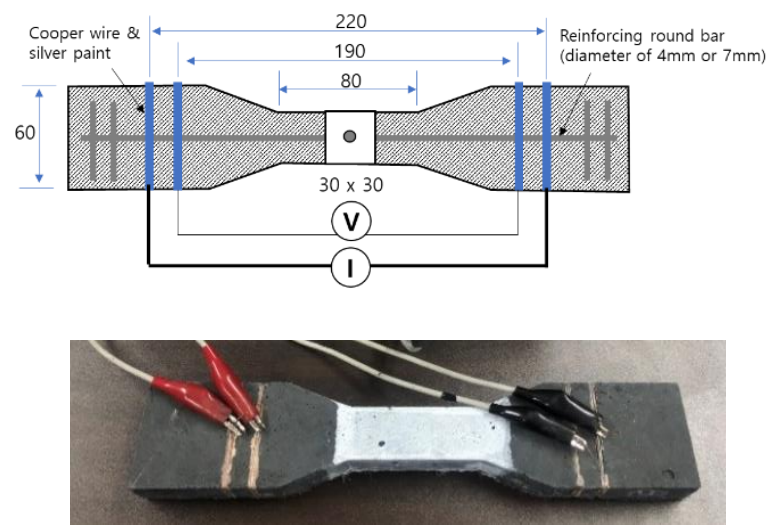

(b)

Figure 1. Manufacture and configuration of PE-SHCC dumbbell-shaped specimen (a) casting the specimen; (b) configuration and dimension of specimen (unit: $\mathrm{mm}$ ).

At three weeks after casting the specimens, four electrodes consisting of fine copper wire were wrapped at the opposing ends of wider portion of each dumbbell-shaped specimen, as shown in Figure 1b. Each copper wire was covered with several layers of silver-based conductive paint to seal any gap and improve the bonding with the tensile specimen to measure the electrical resistance. 


\subsection{Testing Procedure}

After 28 days of curing in standard curing chamber, the dumbbell-shaped specimens with $330 \mathrm{~mm}$ length and cross-sectional dimensions in the narrowed middle region of 30 by $30 \mathrm{~mm}$ were used to investigate the effect of steel reinforcing bar and steel fibers on the direct tensile and self-sensing performances of PE-SHCCs. As shown in Figure 2, direct tensile test was performed in accordance with the recommendations for design and construction of HPFRCCs with multiple fine cracks by the Japan Society of Civil Engineers (JSCE) [28]. Each dumbbell-shaped specimen was aligned in the tensile loading rig and clamped at both ends using wedge-type mechanical grips. Two strain displacement transducers (SDTs) were mounted at the opposing sides of the monitoring portion to monitor the tensile strain and cracks within the narrowed middle region.

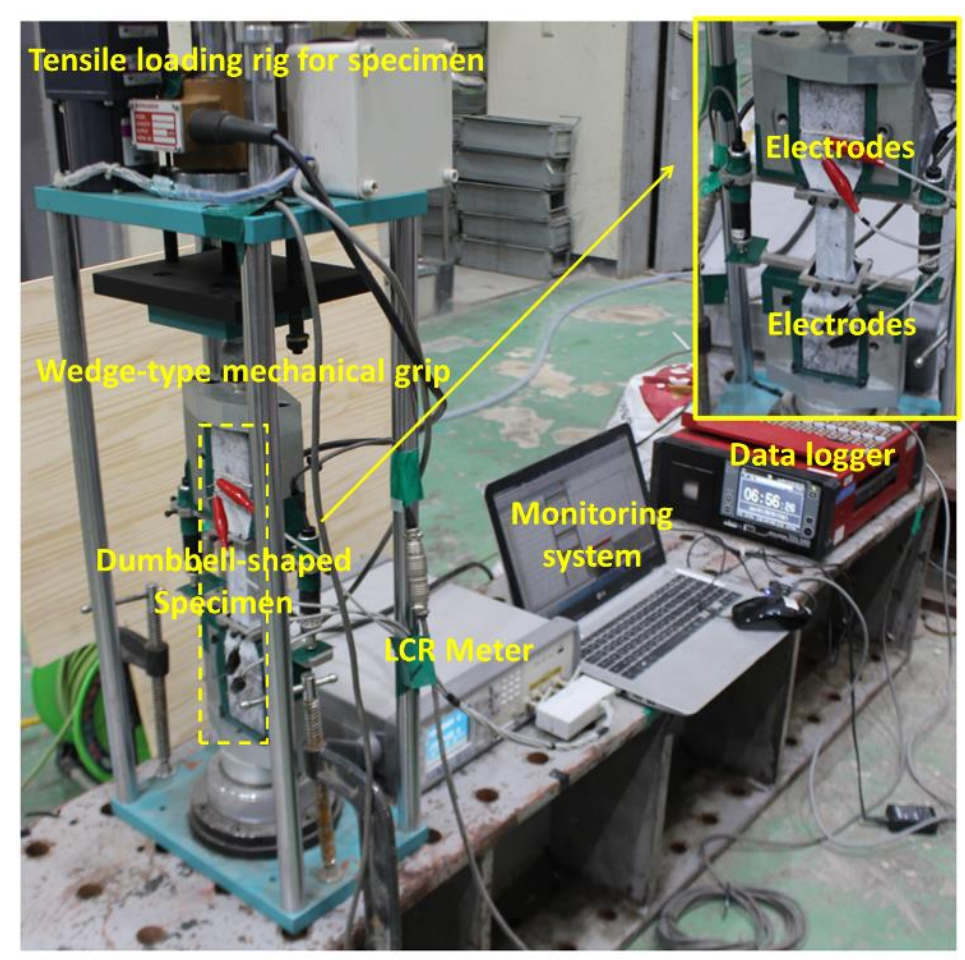

Figure 2. Experimental setup for uniaxial tensile testing and resistivity measurement of dumbbellshaped specimen.

In addition to stress and strain measurement during the tensile loading process, the electrical resistivity of the PE-SHCC specimen was measured in real-time by a fourprobe alternating current (AC) method using a digital LCR meter (Keysight Technologies E4980 AL). The electric current (I) was given to the specimen by using two outer contacts and the two inner contacts were used to measure the voltage difference $(\mathrm{V})$. The setup is shown in Figures $1 \mathrm{~b}$ and 2.

The bulk resistivity $(\rho)$ can be obtained from the following relationship:

$$
\rho=\frac{V \times A}{I \times L}=\frac{R \times A}{L}
$$

where $V$ is the applied AC voltage; I means the electrical current value in ampere; $R$ means the measured electrical resistance in ohm; $A$ indicates the cross-sectional area of the narrowed middle region of the tensile specimen $(0.03 \times 0.03 \mathrm{~m})$; $L$ denotes the distance between voltage measurement electrodes $(0.19 \mathrm{~m})$ 
Sensing performance of cement-based sensors is generally assessed by the fractional change in resistivity (FCR) during loading process. The FCR can be represented as:

$$
\mathrm{FCR}=\frac{\Delta \rho}{\rho_{0}}=\frac{\left(\rho_{t}-\rho_{0}\right)}{\rho_{0}} \approx \frac{\Delta R}{R_{0}}
$$

The sensing sensitivity can be evaluated by gauge factor (GF), which is defined as FCR per unite strain $(\varepsilon)$. The GF is calculated through the following relationship:

$$
\mathrm{GF}=\frac{F C R}{\varepsilon}=\left(\frac{\Delta \rho}{\rho_{0}}\right) / \varepsilon
$$

\section{Results and Discussion}

\subsection{Polarizing Property}

The electrical resistivity of all dumbbell-shaped specimens after 28 days curing was measured using a four-probe method for the first $1800 \mathrm{~s}$ in order to observe the effect of polarization.

Figure 3a illustrates a typical variation of the measured resistivity with durations for the PE-SHCC with 1.0\% steel fiber and 1.0\% MWCNTs without the steel bar (PESHCC-SF10-0), a PE-SHCC-SF10 specimen reinforced with a $4 \mathrm{~mm}$ diameter round bar (PE-SHCC-SF10-4) and a PE-SHCC-SF10 specimen with a $7 \mathrm{~mm}$ diameter round bar (PESHCC-SF10-7), respectively. It can be observed from Figure 3a that the resistivity of PE-SHCC-SF10 mixtures without and with steel bar stabilized and gradually diminished. Figure $3 \mathrm{~b}$ presents the effect of steel bar amount and steel fiber contents on the average resistivity of PE-SHCC dumbbell-shaped specimens before tensile loading.

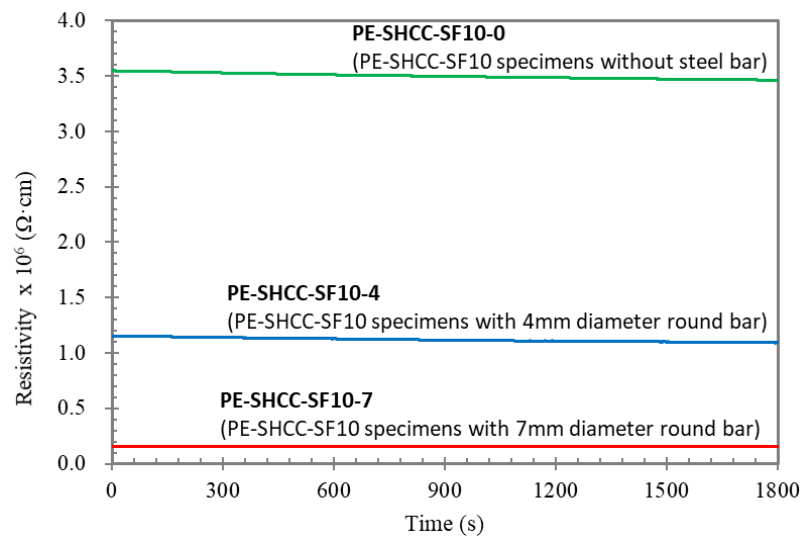

(a)

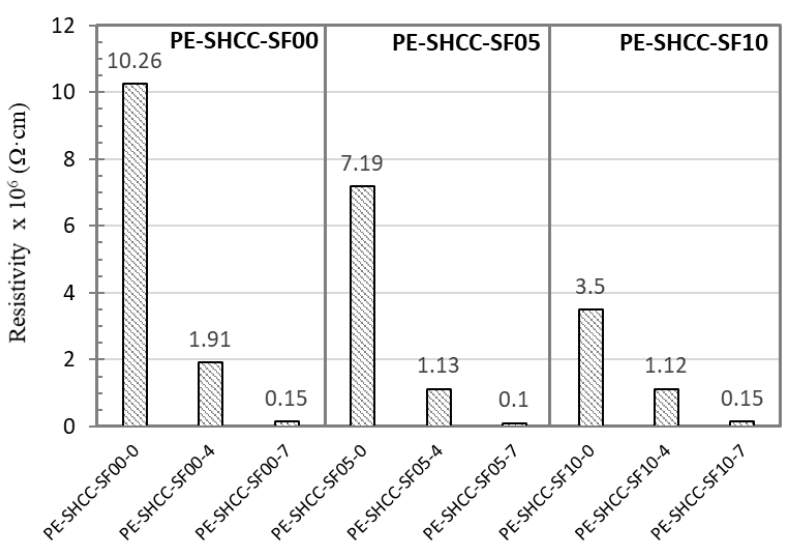

(b)

Figure 3. Variation of the measured resistivity with time for PE-SHCC dumbbell-shaped specimens: (a) the effect of the steel bar on the electrical resistivity variation of the PE-SHCC-SF10 mixture with duration; (b) the effect of the steel bar and steel fibers on the average electrical resistivity of PE-SHCC mixture during the first 1800 seconds.

As shown in Figure 3a,b, the steel bar embedded at the center of the specimen decreases the electrical resistivity of PE-SHCC dumbbell-shaped specimens. As the reinforcing ratio, defined as the ratio between the cross-sectional area of the reinforcing steel bar to the cross-sectional area of the specimen, increased, the electrical resistivity of specimens decreased because of the transmission of the electrical current through steel bar. The consistent result in rectangular beam with rebar in the tensile zone were reported by Wen and Chung [21]. Figure $3 \mathrm{~b}$ indicates that the addition of steel fibers decreases the electrical resistivity of the tensile specimen with and without steel bar. The steel fiber content effect on the resistivity of the PE-SHCC tensile specimen is clearer in the specimen without the 
steel bar. The average electrical resistivity of the PE-SHCC specimens without the steel bar were $10.26 \times 10^{6} \Omega \cdot \mathrm{cm}, 7.19 \times 10^{6} \Omega \cdot \mathrm{cm}$ and $3.50 \times 10^{6} \Omega \cdot \mathrm{cm}$, respectively, for the PE-SHCC mixtures with $0,0.5$ and $1.0 \%$ steel fibers. Consistent results were reported by Song et al. [29] and Banthia et al. [30]. As pointed out by their studies, it is because steel fibers in the PE-SHCC formed the network for conductivity and as the steel fiber content increases, a larger network is constructed that improves the electrical conductivity of cement-based composites such as PE-SHCC. However, for PE-SHCC tensile specimens with a $7 \mathrm{~mm}$ diameter round bar, the polarization variation is not clear according to steel fiber content as shown in Figure 3b. It is apparent that the resistivity of PE-SHCC with steel bar depends mainly on the amount of steel bar and is relatively less dependent on the PE-SHCC matrix.

\subsection{Tensile and Cracking Properties}

Typical stress-strain responses of PE-SHCC dumbbell-shaped specimens with different dosages of steel fibers in direct tension were provided in Figure 4a. All specimens show the representative strain-hardening and multiple cracking behaviors under monotonic tension. Figure $4 \mathrm{~b}$ shows typical stress-strain relationships of PE-SHCC dumbbell-shaped specimens with a $4 \mathrm{~mm}$ diameter round bar in direct tension. In Figure 4 , the tensile stress was calculated with division of the introduced tensile force by a cross-sectional area $(30 \times 30 \mathrm{~mm})$ of the narrowed middle region of the specimen. Additionally, the tensile strain was obtained from dividing the average displacement measured with both SDTs by the gauge length $(100 \mathrm{~mm})$.

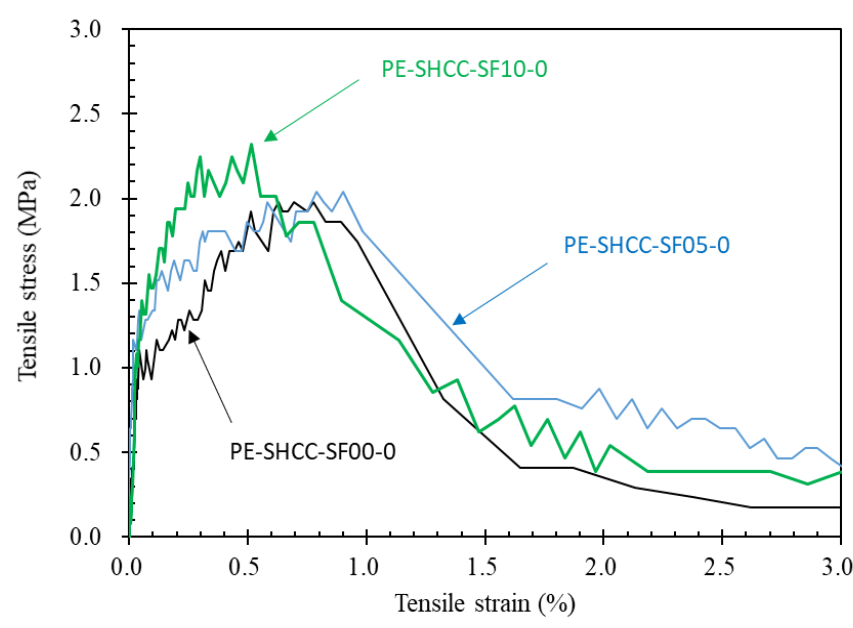

(a)

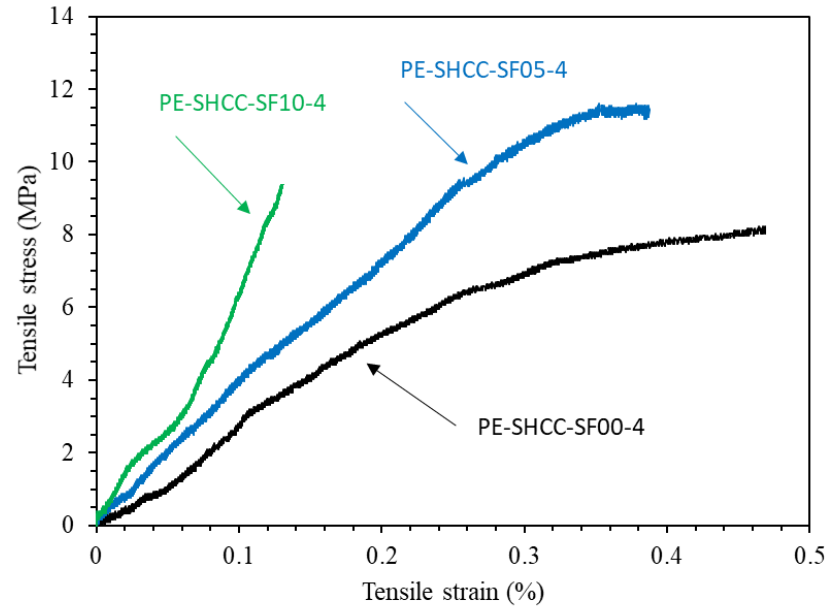

(b)

Figure 4. Typical stress-strain curves of PE-SHCC dumbbell-shaped specimens in direct tension: (a) PE-SHCC tensile specimens without steel bar for 0, 0.5 and 1.0\% steel fibers; (b) PE-SHCC tensile specimens with a 4 mm diameter round bar for $0,0.5$ and $1.0 \%$ steel fibers.

The average tensile strengths of three PE-SHCC tensile specimens with different contents $(0,0.5$ and $1.0 \%)$ of steel fibers were $1.98,2.10$ and $2.43 \mathrm{MPa}$, respectively. Average strain capacities, defined as strain at tensile strength, for the tensile specimens with $0,0.5$ and $1.0 \%$ steel fibers were $1.02 \%, 0.85 \%$ and $0.53 \%$, respectively. As shown in Figure $4 a$, the addition of steel fibers into PE-SHCC mixtures enhanced the tensile strength while strain capacity decreased as the steel fibers contents increased.

The typical stress-strain responses of PE-SHCC dumbbell-shaped specimens with a $4 \mathrm{~mm}$ diameter round bar were presented in Figure 4b. PE-SHCC-SF00-4, PE-SHCC-SF05-4 and PE-SHCC-SF10-4 mean the PE-SHCC tensile specimens with $0,0.5$ and $1.0 \%$ steel fibers. As shown in Figure $4 \mathrm{~b}$, the elastic stiffness (the inclination of stress and strain curve) of PE-SHCC tensile specimens reinforced with a $4 \mathrm{~mm}$ steel bar was steeper due to the 
contribution of steel fibers in resisting the tensile stresses across the macro cracks [31] as the steel fiber contents increased. The tensile responses of PE-SHCC tensile specimens with a $7 \mathrm{~mm}$ diameter round bar are very similar to those of PE-SHCC specimens with a $4 \mathrm{~mm}$ round bar. The tensile tests for PE-SHCC specimens with the steel reinforcing bar were stopped before tensile failure at the narrowed middle region due to local failure at the clamping end of the specimens.

Figure 5 presents typical cracking process of plain PE-SHCC specimens with different content of steel fibers. The figure indicates that the addition of steel fibers has a significant effect on the cracking process of PE-SHCC specimens in direct tension. However, multiple micro cracks were observed in all PE-SHCC specimens.

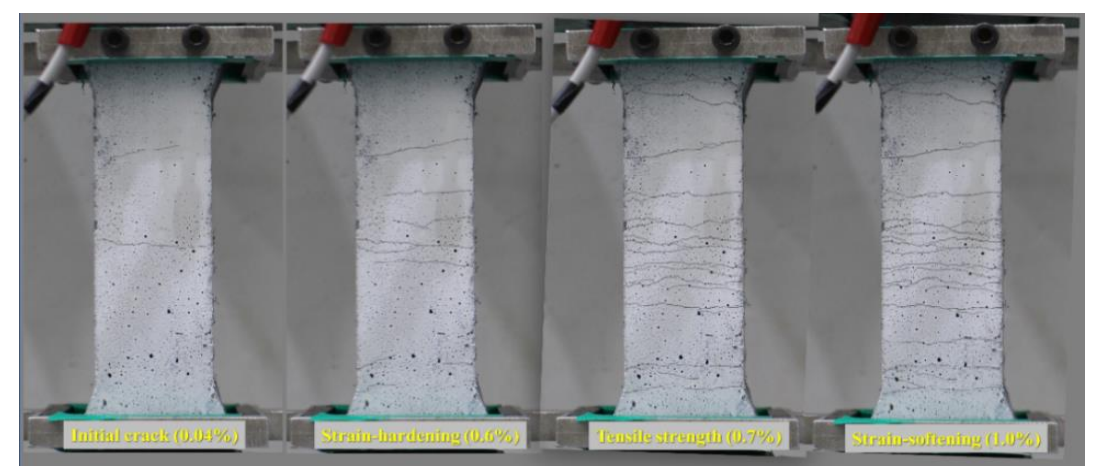

(a)

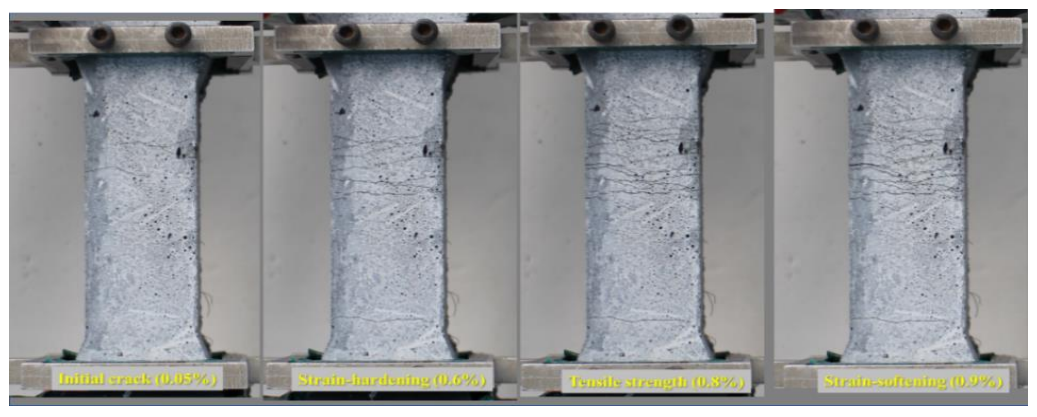

(b)

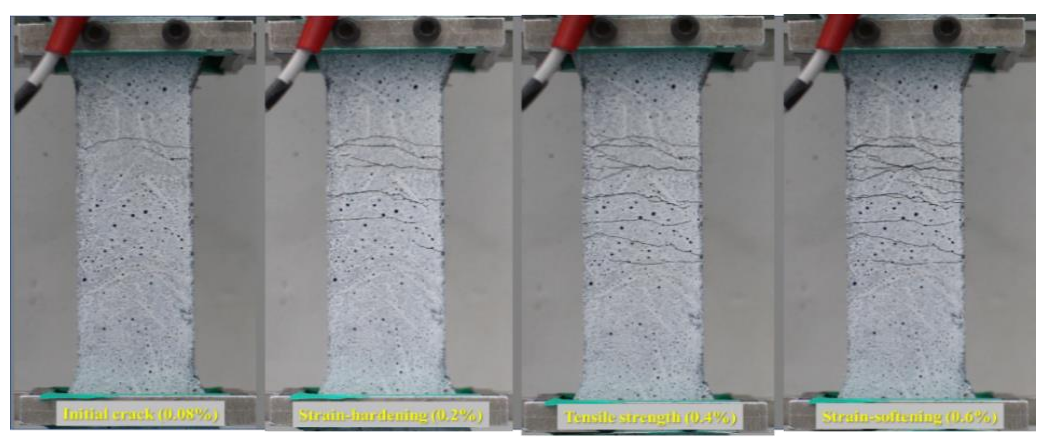

(c)

Figure 5. Typical cracking procedures of PE-SHCC tensile specimens without steel bar: (a) PE-SHCC specimen without steel fibers; (b) PE-SHCC specimen with $0.5 \%$ steel fibers; (c) PE-SHCC specimen with $1.0 \%$ steel fibers.

\subsection{Electrical and Self-Sensing Properties}

The development curves of tensile stress, strain and FCR with duration presented in Figure 6 were compared to investigate the effect of steel fiber content and steel bar on the electrical and tensile properties of PE-SHCC mixtures with 1.0\% MWCNTs. In Figure 6, 
the FCR value for the PE-SHCC specimens with the steel bar is expressed as a percentage different from that of PE-SHCC specimens without the steel bar. As noted in a previous study on the electrical and self-sensing properties of PE-SHCC in repeated compression by the authors [26], Figure 6 shows that the addition of steel fibers also improves the piezoresistive response of PE-SHCC dumbbell-shaped specimens in direct tension.
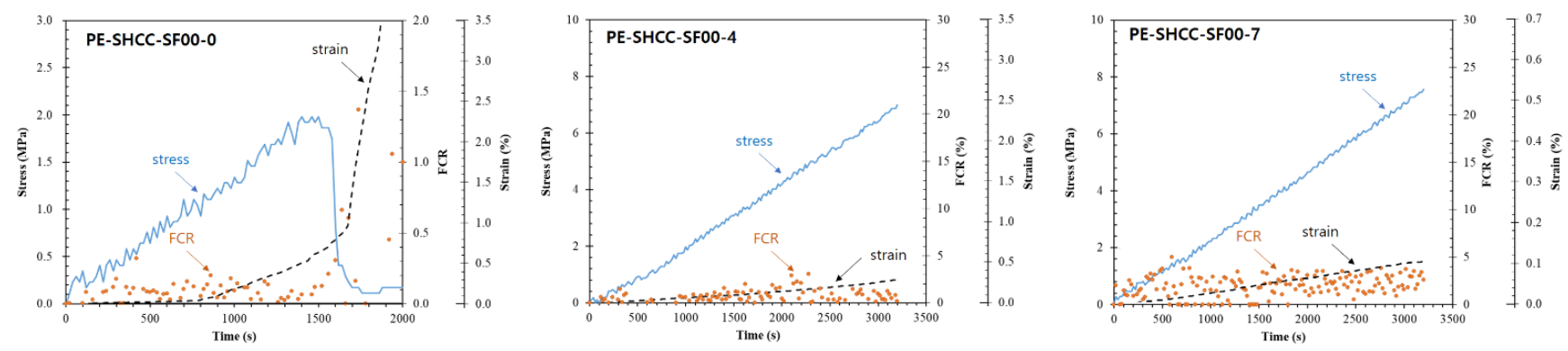

(a)
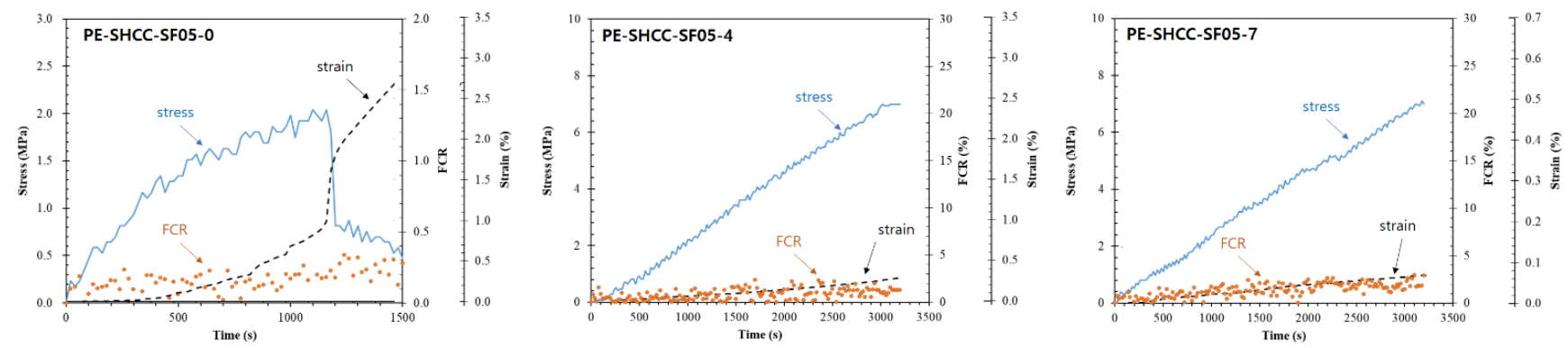

(b)
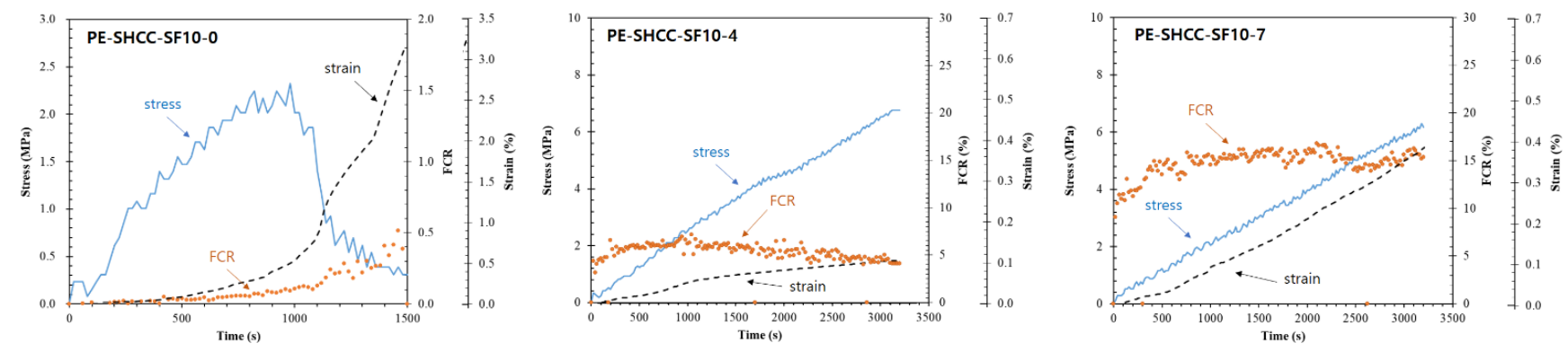

(c)

Figure 6. Typical tensile stress, strain and fractional changes in resistivity (FCR) variation with time: (a) PE-SHCC-SF00 tensile specimens; (b) PE-SHCC-SF05 tensile specimens; (c) PE-SHCC-SF10 tensile specimens.

As the tensile strains in PE-SHCC-SF00-0 and PE-SHCC-SF05-0 specimens increase, FCR contained a lot of noise and was scattered. The trend between tensile strain and FCR was not clear while PE-SHCC-SF10-0 specimens showed a clear trend that FCR increases as tensile strain increases. This tensile-piezoresistive response of SHCCs was reported in several studies $[24,25]$. The reason to increase in FCR under uniaxial loading is that the arrangement of conductive fillers such as steel fibers and MWCNTs slightly changes, resulting in less contact between the conductive fillers and a little increase in FCR of cement-based composites [32].

As the reinforcing ratio of steel bar in the tensile specimen increases, the FCR of PE-SHCC tensile specimens shows more stable variation with tensile strain. Comparison of FCR value in the PE-SHCC specimens with and without steel bar indicates that the FCR value of plain PE-SHCC specimens without steel bar is higher than that of PE-SHCC with steel bar during tensile loading. This is because for PE-SHCC with steel bar, the electrical 
current penetrates largely into steel bar. Since the electrical current penetrating into PESHCC matrix is relatively small, the FCR obtained from the surface resistance variation in the PE-SHCC matrix were not changed significantly although the tensile strain increased.

Figure 7a,b show the typical FCR- tensile strain of plain PE-SHCC specimens with different contents of steel fibers and reinforced PE-SHCC specimens with 1.0\% steel fibers, respectively. As illustrated in Figure 7a, the scatter in the FCR of PE-SHCC-SF00-0 and -SF05-0 specimens is quite large, while the PE-SHCC specimen with $1.0 \%$ steel fibers (PESHCC-SF10) shows a good linear regression between FCR and tensile strain. From these results, it can be concluded that PE-SHCC-SF00-0 and -SF05-0 mixtures may not be used as a cement-based sensor for accurate condition monitoring of civil infrastructures. Figure $7 \mathrm{a}$ indicates that the addition of steel fibers improves the conductive and self-sensing properties of cement-based composites, PE-SHCC mixture.

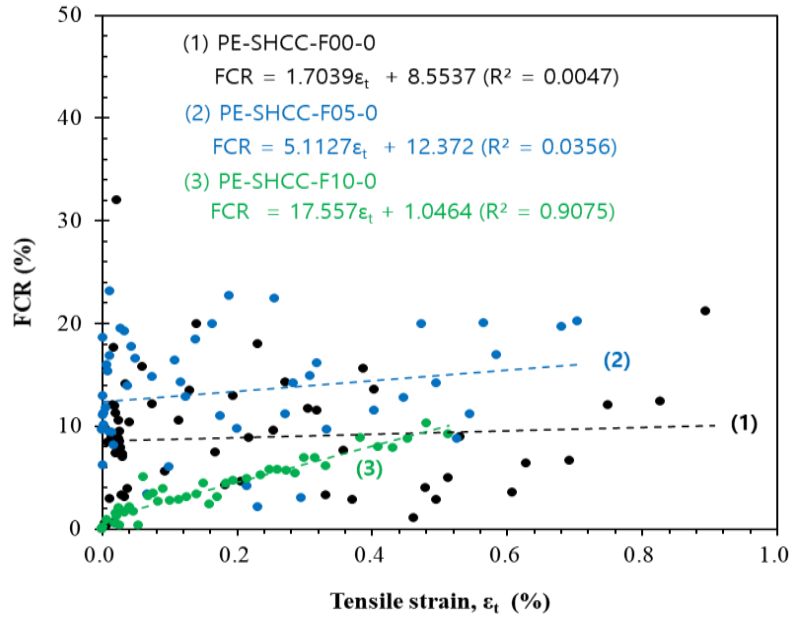

(a)

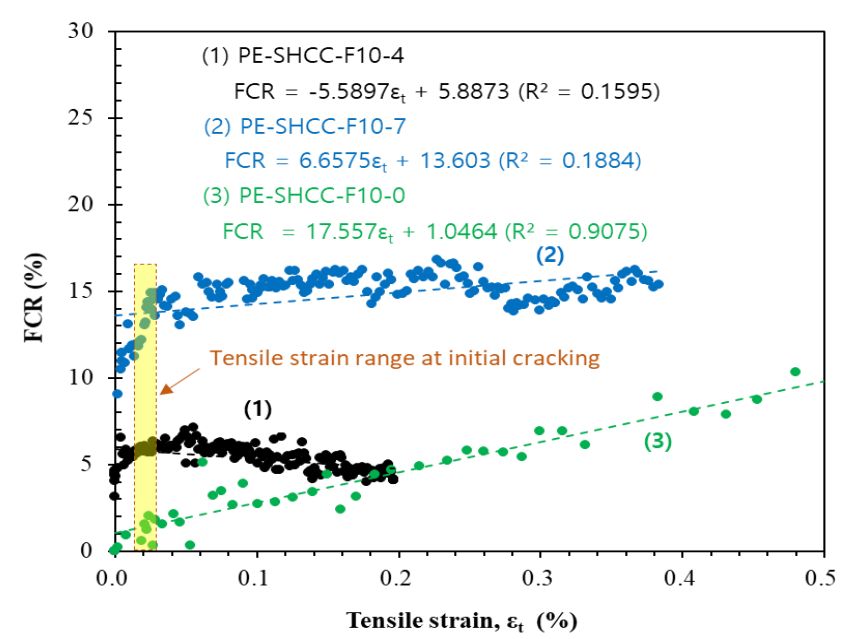

(b)

Figure 7. Typical FCR and tensile strain relationships of PE-SHCC dumbbell-shaped specimens in direct tension: (a) PESHCC tensile specimens without steel bar for $0,0.5$ and 1.0\% steel fibers; (b) PE-SHCC tensile specimens with $1.0 \%$ steel fibers for specimens with a $4 \mathrm{~mm}$ and $7 \mathrm{~mm}$ steel bar.

Figure $7 \mathrm{~b}$ presents the FCR-tensile strain relationship of PE-SHCC-SF10 mixture with and without steel bar and includes the tensile strain range at initial cracking for each specimen. As shown in Figure 7b, the FCR-tensile strain responses showed a stiff slope prior to initial crack. After initial crack, the curves softened and showed a constant value despite the increase in tensile strain. It is concluded from these results that steel reinforcing bar placed at the center of PE-SHCC tensile specimens improves self-sensing performance prior to initial crack but impaired the self-sensing ability after initial crack.

Since the change of FCR in the cement composite was relatively small, even if the amount of steel fiber was increased, the FCR did not show a tendency to change significantly with the increase of tensile strain.

\section{Conclusions}

The influence of steel fiber content and a steel reinforcing bar on the synthetic PE fiber reinforced strain-hardening cement composite (PE-SHCC) with $1.0 \mathrm{wt} \%$ MWCNTs was investigated experimentally in the study. The following conclusion can be drawn from test results.

Electrical polarization during resistivity measurement led to the measured resistivity of PE-SHCC mixtures to decrease slightly with time. The reinforcement of the steel fibers and steel reinforcing bar into PE-SHCC mixture decreased significantly average resistivity measured during the first $30 \mathrm{~min}$ without tensile loading. The incorporation of 0.5 and 1.0 vol.\% steel fibers caused lower resistivity, approximately 0.70 and 0.34 of PE-SHCC 
without steel fiber, respectively. These results indicate that the addition of steel fibers and the placement of steel bar are effective to enhance the conductivity of cement composite reinforced with synthetic fibers.

All the PE-SHCC mixtures with different contents of steel fibers showed multiple cracking and strain-hardening behaviors in direct tension. As steel fiber volume fraction within 1.0 vol.\% increased, the initial cracking and tensile strengths of PE-SHCC specimens increased while strain capacity was decreased.

The FCR values in the plain PE-SHCC specimens increased as the tensile stress and strain increased until tensile strength. After the peak point, FCR increased abruptly. Multiple cracking and strain-hardening behaviors after initial crack led to less contact between conductive materials such as MWCNTs and steel fibers and a steady increase in electrical resistivity of the plain PE-SHCC specimens. The incorporation of the steel fibers and steel bar reduced effectively the error margins and noise in the FCR variation. The self-sensing ability for tensile strain measurements was achieved in synthetic PE fibers reinforced SHCC mixture with 1.0 vol.\% steel fibers, even with 1 wt \% liquid-type MWCNTs. It can be concluded that the steel fiber content of $1.0 \mathrm{vol} \%$ is optimal for the self-sensing performance of the PE-SHCC mixture with $1.0 \mathrm{wt} \%$ MWCNTs.

The higher GF in the plain PE-SHCC specimens with $1.0 \mathrm{wt} \%$ MWCNTs under direct tension was obtained from adding 1.0 vol.\% steel fibers. At the initial loading stage, prior to the initial crack, the self-sensing ability of the PE-SHCC-SF10 specimens was improved by the presence of the embedded steel bar while the PE-SHCC-SF10 specimens with the steel bar were less sensitive as the tensile strain increased after initial crack.

Author Contributions: Conceptualization, H.-D.Y., S.-Y.S. and M.-S.L.; methodology, S.-W.K., W.-S.P. and D.-H.K.; investigation, S.-W.K., W.-S.P. and D.-H.K.; data curation, S.-W.K. and D.-H.K.; writing-original draft preparation, H.-D.Y. and D.-H.K.; writing-review and editing, S.-Y.S. and M.-S.L.; visualization, S.-W.K. and W.-S.P.; supervision, H.-D.Y. All authors have read and agreed to the published version of the manuscript.

Funding: This research was funded by National Research Foundation (NRF) of Korea, grant number 2018R1A4A1025953.

Institutional Review Board Statement: Not applicable.

Informed Consent Statement: Not applicable.

Conflicts of Interest: The authors declare no conflict of interest.

\section{References}

1. Tian, Z.; Li, Y.; Zheng, J.; Wang, S. A state-of-the-art on self-sensing concrete: Materials, fabrication and properties. Compos. Part B Eng. 2019, 177, 107437. [CrossRef]

2. Han, J.; Pan, J.; Cai, J.; Li, X. A review on carbon-based self-sensing cementitious composites. Constr. Build. Mater. 2020, 265, 120764. [CrossRef]

3. Vlachakis, C.; Perry, M.; Biondi, L. Self-sensing alkali-activated materials: A review. Minerals 2020, 10, 885. [CrossRef]

4. Ding, Y.; Liu, G.; Hussain, A.; Pacheco-Torgal, F.; Zhang, Y. Effect of steel fiber and carbon black on the self-sensing ability of concrete cracks under bending. Constr. Build. Mater. 2019, 207, 630-639. [CrossRef]

5. Xiao, H.; Liu, M.; Wang, G. Anisotropic electrical and abrasion-sensing properties of cement-based composites containing aligned nickel powder. Cem. Concr. Compos. 2018, 87, 130-136. [CrossRef]

6. Li, C.; Thostenson, E.T.; Chou, T.W. Sensors and actuators based on carbon nanotubes and their composites: A review. Compos. Sci. Technol. 2008, 68, 1227-1249. [CrossRef]

7. Wang, L.; Aslani, F. A review on material design, performance, and practical application of electrically conductive cementitious composites. Constr. Build. Mater. 2019, 229, 116892. [CrossRef]

8. Yoo, D.-Y.; You, I.; Lee, S.-J. Electrical properties of cement-based composites with carbon nanotubes, graphene, and graphite nanofibers. Sensors 2017, 17, 1064. [CrossRef] [PubMed]

9. Dong, W.; Li, W.; Wang, K.; Luo, Z.; Sheng, D. Self-sensing capabilities of cement-based sensor with layer-distributed conductive rubber fibres. Sens. Actuators A Phys. 2020, 301, 111763. [CrossRef]

10. Yin, T.; Xu, J.; Wang, Y.; Liu, L. Increasing self-sensing capability of carbon nanotubes cement-based materials by simultaneous addition of Ni nanofibers with low content. Constr. Build. Mater. 2020, 254, 119306. [CrossRef] 
11. Yang, P.; Chowdhury, S.; Neithalath, N. Strain sensing ability of metallic particulate reinforced cementitious composites: Experiments and microstructure-guided finite element modeling. Cem. Concr. Compos. 2018, 90, 225-234. [CrossRef]

12. Rana, S.; Subramani, P.; Fangueiro, R.; Correia, A.G. A review on smart self-sensing composite materials for civil engineering applications. AIMS Mater. Sci. 2016, 3, 357-379. [CrossRef]

13. Han, B.; Ding, S.; Yu, X. Intrinsic self-sensing concrete and structures: A review. Measurement 2015, 59, 110-128. [CrossRef]

14. Sarwary, M.H.; Yıldırım, G.; Al-Dahawi, A.; Anıl, Ö.; Khiavi, K.A.; Toklu, K.; Şahmaran, M. Self-sensing of flexural damage in large-scale steel-reinforced mortar beams. ACI Mater. J. 2019, 116, 209-221. [CrossRef]

15. Howser, R.N.; Dhonde, H.B.; Mo, Y.L. Self-sensing of carbon nanofiber concrete columns subjected to reversed cyclic loading. Smart Mater. Struct. 2011, 20, 085031. [CrossRef]

16. Roopa, A.K.; Hunashyal, A.M.; Venkaraddiyavar, P.; Ganachari, S.V. Smart hybrid nano composite concrete embedded sensors for structural health monitoring. Mater. Today Proc. 2020, 27, 603-609. [CrossRef]

17. Dong, W.; Li, W.; Luo, Z.; Long, G.; Vessalas, K.; Sheng, D. Structural response monitoring of concrete beam under flexural loading using smart carbon black/cement-based sensors. Smart Mater. Struct. 2020, 29, 065001. [CrossRef]

18. Wen, S.; Chung, D.D.L. Carbon fiber-reinforced cement as a strain-sensing coating. Cem. Concr. Res. 2001, 31, 665-667. [CrossRef]

19. Wang, W.; Dai, H.; Wu, S. Mechanical behavior and electrical property of CFRC-strengthened RC beams under fatigue and monotonic loading. Mater. Sci. Eng. A 2008, 479, 191-196. [CrossRef]

20. Wen, S.; Chung, D.D.L. Self-sensing of flexural damage and strain in carbon fiber reinforced cement and effect of embedded steel reinforcing bars. Carbon 2006, 44, 1496-1502. [CrossRef]

21. Paul, S.C.; Babafemi, A.J. A review of the mechanical and durability properties of strain hardening cement-based composite (SHCC). J. Sustain. Cem. Based Mater. 2018, 7, 57-78. [CrossRef]

22. Choi, W.C.; Yun, H.D.; Cho, C.G.; Feo, L. Attempts to apply high performance fiber-reinforced cement composite (HPFRCC) to infrastructures in South Korea. Compos. Struct. 2014, 109, 211-223. [CrossRef]

23. Lin, V.W.; Li, M.; Lynch, J.P.; Li, V.C. Mechanical and electrical characterization of self-sensing carbon black ECC. In Nondestructive Characterization for Composite Materials, Aerospace Engineering, Civil Infrastructure, and Homeland Security 2011; International Society for Optics and Photonics: San Diego, CA, USA, 2011; Volume 7983, p. 798316.

24. Huang, Y.; Li, H.; Qian, S. Self-sensing properties of engineered cementitious composites. Constr. Build. Mater. 2018, 174, 253-262. [CrossRef]

25. Yıldırım, G.; Öztürk, O.; Al-Dahawi, A.; Ulu, A.A.; Şahmaran, M. Self-sensing capability of Engineered Cementitious Composites: Effects of aging and loading conditions. Constr. Build. Mater. 2020, 231, 117132. [CrossRef]

26. Jang, A.Y.; Lim, S.H.; Kim, D.H.; Yun, H.D.; Lee, G.C.; Seo, S.Y. Strain-Detecting properties of hybrid PE and steel fibers reinforced cement composite (Hy-FRCC) with Multi-Walled carbon nanotube (MWCNT) under repeated compression. Results Phys. 2020, 18, 103199. [CrossRef]

27. Banthia, N.; Nandakumar, N. Crack growth resistance of hybrid fiber reinforced cement composites. Cem. Concr. Compos. 2003, 25, 3-9. [CrossRef]

28. Japan Society of Civil Engineers. Recommendations for Design and Construction of High Performance Fiber Reinforced Cement Composite with Multiple Fine Cracks (Draft); Concrete Library: Concrete, WA, USA, 2007; Volume 127.

29. Song, J.; Nguyen, D.L.; Manathamsombat, C.; Kim, D.J. Effect of fiber volume content on electromechanical behavior of strain-hardening steel-fiber-reinforced cementitious composites. J. Compos. Mater. 2015, 49, 3621-3634. [CrossRef]

30. Banthia, N.; Djeridane, S.; Pigeon, M. Electrical resistivity of carbon and steel micro-fiber reinforced cements. Cem. Concr. Res. 1992, 22, 804-814. [CrossRef]

31. Jang, S.J.; Kim, J.H.; Kim, S.W.; Park, W.S.; Yun, H.D. The effect of shrinkage-compensation on the performance of strain-hardening cement composite (SHCC). Sustainability 2019, 11, 1453. [CrossRef]

32. Azhari, F.; Banthia, N. Carbon Fiber-Reinforced Cementitious Composites for Tensile Strain Sensing. ACI Mater. J. 2017, 114, 129-136. 